\title{
BLICKDIAGNOSE
}
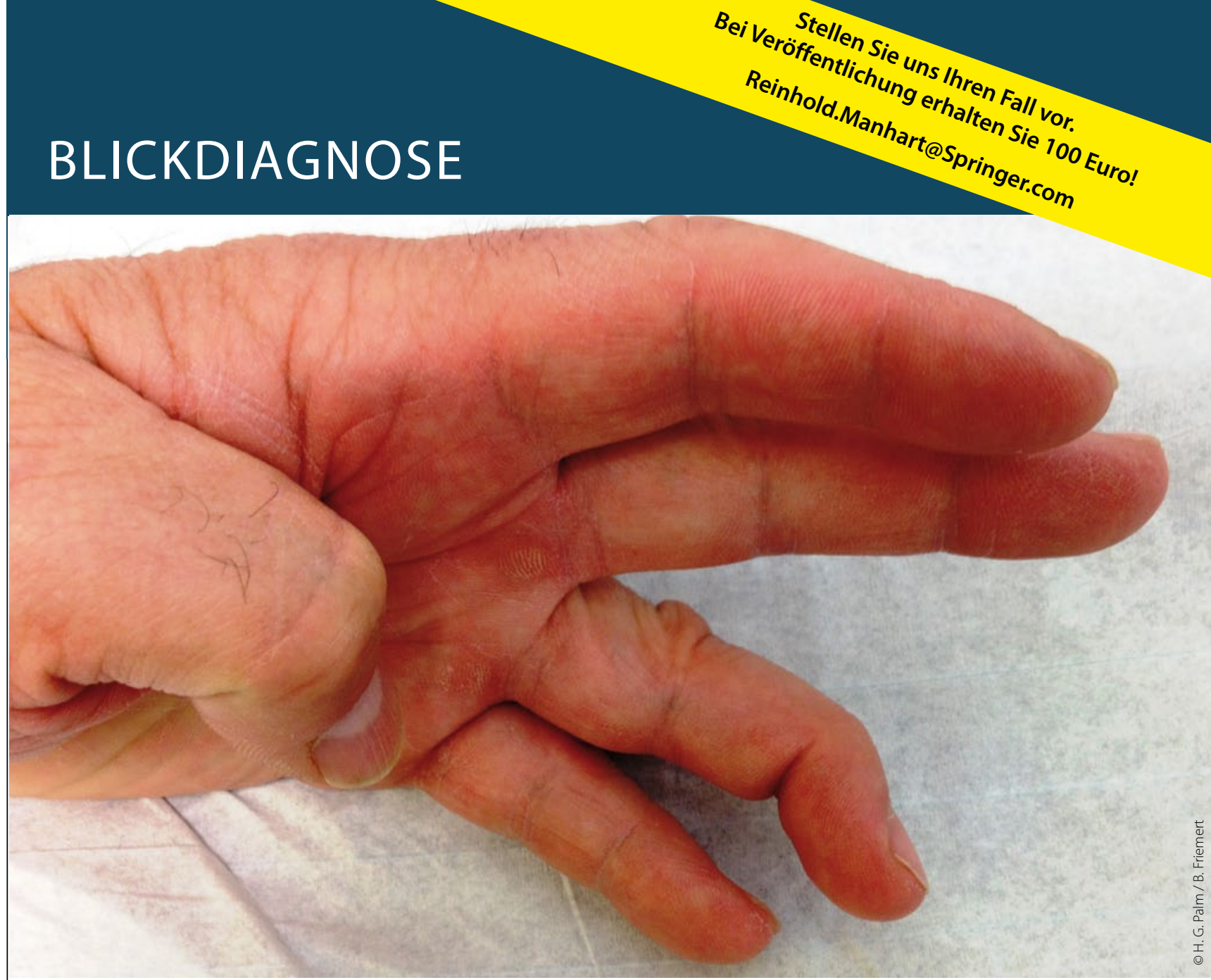

Kennen Sie diese Sportverletzung?

\section{Ein Hammer, dieser Finger!}

— Ein 38-jähriger Volleyballspieler stellte sich mit der abgebildeten Fehlstellung des vierten Fingerendgelenkes vor, nachdem ein Ball axial auf den ausgestreckten Finger gefallen war. Die aktive Streckung im Endgelenk war aufgehoben, die Beugung aber problemlos durchführbar. Ein neurologisches Defizit bestand nicht.

Das klinische Bild eines sog. „Hammerfingers“, die Anamnese mit traumatischer Beugung des Fingerendgelenkes und die Unfähigkeit, aktiv zu strecken, weisen auf eine Strecksehnenruptur hin. Diese wird in der Regel konservativ mit strenger Ruhigstellung, d. h. mit dem Tragen einer Stack'schen Schiene für ca. sechs Wochen, therapiert. Eine operative Versorgung ist insbesondere dann indiziert, wenn es sich um knöcherne Sehnenausrisse handelt, da bei Dislokation eines größeren Knochenpartikels Funktionsverlust und Arthrose drohen.

\section{Keywords: mallet finger}

- Oberstabsarzt Dr. Hans-Georg Palm, Oberstarzt Prof. Dr. Benedikt Friemert, Klinik für Unfallchirurgie und Orthopädie am Bundeswehrkrankenhaus UIm

\section{Weitere Infos auf springermedizin.de}

Weitere Fälle unserer Leser finden Sie im Internet unter: - www.springermedizin.de/blickdiagnose 